\title{
O Empoderamento da Teologia durante a Pandemia
}

\author{
Theology Empowerment during Pandemic
}

Fábio Luiz Ribeiro

\section{Resumo}

O presente artigo visa suscitar a discussão sobre a efetividade e a natureza de duas formas de relações humanas potencializadas pela situação de isolamento, decorrente do atual quadro da pandemia da Covid-19 declarado pela ONU. A primeira destas formas é a participação do ambiente virtual pela Instituição Eclesial, diante da marcante necessidade de possibilitar a realização de celebrações de fé em contexto comunitário. Diante de diversas interpretações do significado da mediação tecnológica nas relações humanas, desenvolve-se o conceito de mundo real-virtual, uma vez que não se prescinde da natureza corpórea para a vivência das experiências por meio da rede. A segunda forma de relações é a que ocorre nos lares dos crentes, assistida pela Igreja institucional, que atua como mãe das Igrejas domésticas, com seu patrimônio de Fé e apresentando uma resposta às necessidades de ordem material, espiritual e cognitiva às famílias fragilizadas pelas restrições sanitárias que lhes foram impostas. Ambas as relações abordadas sinalizam a existência de um locus privilegiado para a atuação da Teologia Prática, na orientação das atuações dos templos religiosos em seus espaços sociais de influência, mediante a reflexão sobre o modo pelo qual a mensagem de Cristo deve ser posta em ação.

Palavras-chave: Pandemia e Teologia Prática. Mundo real-virtual. Relações eclesiológicas virtuais. Igrejas domésticas. Comunidades virtuais de fé. 


\begin{abstract}
This article aims to raise the discussion on the effectiveness and nature of two forms of human relationships that are enhanced by the situation of isolation, resulting from the current situation of the Covid-19 pandemic declared by the $\mathrm{UN}$. The first of these forms is the participation of the virtual environment by the Ecclesial Institution, given the strong need to make it possible to hold celebrations of faith in a community context. Faced with various interpretations of the meaning of technological mediation in human relations, the concept of the real-virtual world is developed, since the corporeal nature is not dispensed with for the experiences through the network. The second form of relationships is that which occurs in the homes of believers, assisted by the institutional Church, which acts as the mother of domestic Churches, with its heritage of Faith and presenting a response to the needs of material, spiritual and cognitive order to families weakened by restrictions health conditions imposed on them. Both of the relationships discussed signal the existence of a privileged locus for the performance of Practical Theology, in guiding the activities of religious temples in their social spaces of influence, through reflection on the way in which the message of Christ should be put into action.
\end{abstract}

Keywords: Pandemic and Practical Theology. Real-virtual world. Virtual ecclesiological relations. In house churches. Virtual communities of Faith.

\title{
Introdução
}

A irrupção do novo coronavírus impactou o planeta, deixando sequelas socioeconômicas e políticas que só ulteriormente poderão ser avaliadas. O assunto começou a ganhar as manchetes a partir de 31 de dezembro de 2019, quando o governo chinês comunicou oficialmente à Organização Mundial da Saúde (OMS) que, no início daquele mês, em Wuhan, cidade da província de Hubei, havia se manifestado o que então chamava de "pneumonia de causa desconhecida". Em janeiro do ano seguinte a China registrou o primeiro óbito decorrente da nova moléstia de cunho viral que logo demonstrou ser altamente transmissível e mortífera. Pior: ela não tardou a superar as fronteiras do país de origem e se alastrar mundo afora.

Chegado o mês de fevereiro de 2020, a ciência deu um apelativo para a referida enfermidade que já começava a assustar o planeta: Covid-19. No dia 
26 daquele mês o mal atingiu o Brasil, dado que em São Paulo-SP se registrou o primeiro caso comprovado de contágio. Em março seguinte, e outra vez em São Paulo, aconteceu o que se temia: o decesso de uma senhora de 57 anos. Justo naquele mês a OMS reconheceu que havia uma pandemia em curso, coisa que o Brasil iria comprovar por experiência própria, inclusive porque em breve se tornaria um dos epicentros dela. Tanto assim que, em janeiro de 2021, o país contabilizaria 200.498 falecidos ao lado de mais de 7 milhões de infectados, sem que houvesse perspectiva de melhora.

Entrementes, a pesquisa científica não media esforços para encontrar vacinas e, quando surgiram resultados satisfatórios, no Brasil, em que pese os desacertos políticos internos, a Agência Nacional de Vigilância Sanitária (ANVISA) procurou adquirir e aplicar tais antivírus. O momento urgia porque a ameaça de colapso do sistema sanitário brasileiro e a sobrecarga nos cemitérios se tornavam patentes. Outro elemento complicador foram as falhas na coordenação nacional; mas, cada unidade da Federação procurou refrear o contágio adequando-se tanto quanto possível às medidas recomendadas pelas agências de saúde internacionais. Dentre elas figuravam o distanciamento social, o uso de máscaras, frequente higienização das mãos e mesmo, quarentena. Não se tratou de uma opção totalmente tranquila, pois, ditos protocolos sanitários, com o passar do tempo provocaram cansaço em muitos, sem falar que a diminuição da atividade econômica causada pelo distanciamento social que gerou desemprego e recessão.

A referida conjuntura teve influxos severos também em âmbito religioso, na medida que forçou os distintos cultos a procurarem saídas, tais como celebrações "virtuais". No que diz respeito ao Catolicismo, suas práticas litúrgicas também se adaptaram a tais recursos técnicos, os quais lhe forneceram os meios necessários para atingir os lares. De outra feita, o laicato fiel também se reorganizou, alterando seus hábitos e reorientando a informática doméstica para estes novos fins. $\mathrm{O}$ fenômeno se alargou, superando limites confessionais e culturais e daí, tanto personagens famosas quanto cidadãos comuns passaram a realizar produções caseiras, modestas quanto aos meios, mas ricas de criatividade. Envolveram-se na novidade também grupos de educadores, e até mesmo pessoas pouco afeitas a mudanças. Por este mister, tornaram-se repentinamente populares tanto a participação em videoconferências quanto a utilização de meios remotos para ministrar lições. À mesma iniciativa se associaram classes várias de trabalhadores, a exemplo dos que atuam em caravanas, "sacoleiros", e categorias mais. Eles se curvaram à evidência que o comércio eletrônico, além de ser viável, é também producente. 
Nas atividades pastorais das igrejas dentro da realidade da pandemia, malgrado certas contestações havidas, o apelo aos meios eletrônicos passou a ser concebido não apenas como uma solução, mas também como uma saída imprescindível perante o desafio que se coloca, sobretudo para a vida cultual daqueles que creem, buscam conforto e esperança nas igrejas. Desse modo, agentes de pastoral não titubearam em lançar mão dos citados meios midiáticos para realizarem suas ações, dando origem a lives e cerimônias realizadas via internet. Organizaram similarmente atividades litúrgicas "em rede" que, não obstante o caráter inusitado, propiciaram maior participação comunitária, sempre graças à mesma internet. Dito de outra forma, a difusão de seus conteúdos, no contexto virtual, proporcionou o "empoderamento" da teologia. ${ }^{1}$ Nestes mesmos meios igualmente se criou novo espaço para o culto on-line, bem como o compartilhamento da fé nas distintas igrejas domésticas. ${ }^{2}$

\section{Interação midiática}

A interação entre os meios de comunicação social conduziu a maneiras inéditas de se realizar o encontro nas várias instâncias da sociedade entre o contato presencial e virtual. Nesse pressuposto, tornou-se necessário não apenas dominar o uso desses recursos disponíveis, mas também cuidar da elaboração dos conteúdos que se desejava comunicar. ${ }^{3}$ Outro detalhe nada secundário tem a ver com o alcance desses meios, que abrem um leque de possibilidades jamais visto antes.

No caso específico da relação mídia-Igreja, suas variantes e perspectivas são desafios imediatos, até porque, através do uso desses meios técnicos, são também abordadas sensíveis questões de fé, sem falar que a aplicação deles não é uniforme na ambiência eclesial. Tenha-se do mesmo modo presente que, nos nossos dias, o que uma igreja faz a nível presencial pode ser também realizado de modo remoto através da internet. Percebe-se, outrossim, que determinadas funções, especialmente aquelas mais pertinentes à difusão de ensinamentos teológicos, podem ser comunicadas com maiores facilidades, enquanto outras,

\footnotetext{
${ }^{1}$ A palavra deriva do verbo inglês "to empower" que significa: dar poder ou autoridade, obter mais controle sobre a própria vida ou sobre uma situação em que vivem as pessoas, ativar as forças e as capacidades que a pessoa já tem, mas que não foram desenvolvidas ainda. No campo teológico a expressão traduz a ideia de força assumida. Uma tradução melhor seria "investidura". 2 ADAM, J. C.; REBLIN, I. A.; SALDANHA, M. R., Igreja em rede e liturgia on-line, é possível?, p. 599-600.

3 ADAM, J. C.; REBLIN, I. A.; SALDANHA, M. R., Igreja em rede e liturgia on-line, é possível?, p. 600 .
} 
sobretudo as relacionadas aos cultos e sacramentos, mesmo que igualmente transmitidas, não são verdadeiramente experienciadas através dos meios de comunicação de massa. Há também um entendimento mais severo, que compreende os recursos midiáticos somente como uma solução para apoiar as tarefas presenciais na igreja. Este pensamento duvidoso necessita ser superado: aquele que sustenta que a interação entre a tecnologia, linguagem e a mídia não é verdadeira. Pode-se, ao invés, afirmar que ela é tão autêntica e legítima, apesar de advir numa forma diferente, dado que a mídia possui metodologia distinta, bem como o espaço e o tempo. Ou seja, conta com uma linguagem específica. Portanto, a assertiva de que inexiste comunidade na rede, é infundada. Falta nela uma comunidade fisicamente presente, mas há, de fato, ainda que em forma dissímile, uma presença comunitária real, quiçá mais extensa que o grupo social que fisicamente se reúne. Este pré-entendimento é básico para se delinear e estabelecer aquilo que será comunicado pelas redes sociais. ${ }^{4}$

Alguns entendimentos teológicos e confessionais, todavia, são ainda trazidos para o diálogo quando se pensa sobre o uso da mídia na Igreja ou mesmo sobre a presença da Igreja na mídia. Tem-se, nessa direção, um pensar da mídia a partir da Teologia e um pensar da Teologia a partir da mídia. ${ }^{5}$ Isso constitui que o uso ou não de mídias ou ainda a existência ou não de uma igreja numa realidade midiatizada é determinado também por temas teológicos, confessionais e eclesiológicos, que são problematizados e rediscutidos e, de modo inclusivo, alterados em ocasiões de crise. Refletindo sobre o trabalho ministerial, o panorama pandêmico atual leva a refletir sobre o que é o fundamental e que deve orientar a vida comunitária e na igreja, a ser realizado por meio da mídia. ${ }^{6}$

A atuação dos meios de comunicação social e da tecnologia de informação em uma sociedade acaba sempre a modificando, transformando costumes, alterando hábitos, percepções de mundo e outros. Igualmente, se toda a vida tem se midiatizado, não seria diferente com a experiência religiosa, a vivência da fé e a participação na igreja. De tal modo, vale observar que "a discussão sobre essa relação também já é de longa data. Exemplo disto foi visto já na década de 1960, a partir do Concílio Vaticano II, quando a Igreja Católica

\footnotetext{
${ }^{4}$ ADAM, J. C.; REBLIN, I. A.; SALDANHA, M. R., Igreja em rede e liturgia on-line, é possível?, p. 601.

${ }^{5}$ SPADARO, A., Ciberteologia, p. 39.

${ }^{6}$ ADAM, J. C.; REBLIN, I. A.; SALDANHA, M. R., Igreja em rede e liturgia on-line, é possível?, p. 601.
} 
lançou o documento Inter Mirifica, que reflete e regulamenta os usos das mídias na igreja". ${ }^{7}$

A interrelação entre internet e os meios midiáticos não é simplesmente um meio, mas sim uma inovação da linguagem em rede, por meio da qual se articula um original modo de se posicionar no mundo. Torna-se imperioso compreender seu alcance e variadas aplicabilidades na sociedade hodierna, até porque já se especula que também a Igreja em sua realidade atual poderá ser definitivamente on-line, não obstante seja ainda cedo para avaliar o impacto dessa possibilidade, caso se concretize. Para alguns isso pode soar inverossímil; mas, já agora sucede educação à distância e se multiplicam os casos de afetos que nascem nos sites de relacionamento. ${ }^{8}$ De qualquer forma, a prudência recomenda cautela, se se tem presente que as aceleradas mudanças sociais que se verificam poderão subverter esta lógica e trazer fatos novos.

Por sua vez, as grandes religiões da humanidade testemunham, não raro de modo impressionante, o valor e o respeito que o culto tem como fonte e vida da igreja. No centro do rito celebrado pressupõe-se que tudo aquilo que a igreja celebra parte do seu rito e regressa a ele. Assim, a igreja pode abster-se de diversas de suas funções, movimentos, e planos, mas não sem celebrar. Este princípio mostrou toda sua concretude nos tempos de pandemia e de distanciamento social. Como não rezar a Páscoa, acontecimento principal da igreja e da fé dos cristãos? E além disso: precisamente diante da gigantesca crise humanitária, como a pandemia do coronavírus, como não proclamar a palavra de Deus? Como não anunciar o Evangelho? Como não rezar em comunidade? Perante essas questões, outra deve ser recolocada: é admissível fazer da rede um instrumento para a ação litúrgica? ${ }^{9}$

Ao se considerar, principalmente a internet e fazendo uma análise das conjunturas sociais que ela causou a partir de sua efetivação nos anos de 1990, pode-se assegurar mais: atualmente tem instituições que não exclusivamente fazem uso da rede, mas, de fato, existem também na rede. ${ }^{10}$ Uma teologia encarnada ou inserida na realidade atual da população está sempre em constante reflexão, procurando interagir e dialogar até mesmo com outras ciências no

\footnotetext{
${ }^{7}$ ADAM, J. C.; REBLIN, I. A.; SALDANHA, M. R., Igreja em rede e liturgia on-line, é possível?, p. 602.

8 ADAM, J. C.; REBLIN, I. A.; SALDANHA, M. R., Igreja em rede e liturgia on-line, é possível?, p. 602-603.

9 ADAM, J. C.; REBLIN, I. A.; SALDANHA, M. R., Igreja em rede e liturgia on-line, é possível?, p. 603.

${ }^{10}$ CAMPOS L. S., Igrejas cristãs brasileiras e cultura midiática, p. 123-168.
} 
intuito de responder as demandas atuais do mundo. ${ }^{11}$ É nesta realidade desafiadora da pandemia que as ciências biológicas e médicas mostram suas forças, mas também a teologia assume sua força, sua investidura, seu poder e firma-se diante da política em afirmar que suas celebrações são serviços essenciais, além de seu empoderamento nos vários veículos de imprensa e mídias sociais.

Uma vez superada a ocasião da pura reação, o que abriu espaço para celebrações digitalizadas como solução imediata ao distanciamento, coloca-se o desafio sobre como se ajustar ao uso da rede, inclusive para se pensar a vida litúrgica a partir dela. Pressupondo-se, com base no dado da fé, que a existência humana é algo maior do que o simples estar no mundo, entende-se que a vida do homem se caracteriza por contínuo crescimento, o qual geralmente é motivado pela ânsia de novos conhecimentos, descobertas e conquistas. Conceber, portanto, numa celebração em rede, pressupõe o ir além da etapa atual, para daí se aprimorar a celebração através dos mecanismos digitais. ${ }^{12}$ Esta metodologia, a bem da verdade, já está em uma direção completa, haja visto que se multiplicam as diversas configurações de se expor temáticas teológicas, as quais se tornam cada vez ascendentes, enobrecidas como são pelos elementos que a mesma rede disponibiliza.

A propósito, as experiências teológicas vivenciadas no atual período pandêmico, evidenciam que o tempo e o espaço do culto mediados pela rede estão preenchidos com potenciais promissores. De acordo com Hegel, ${ }^{13}$ podese afirmar que a veracidade dos fatos é constituída por um agir dialético que parte da declaração de uma questão, passa por um indeferimento, para, então, proceder à negação da negação, o que conduz à um coeso processo necessário para se entender um acontecimento ou fenômeno. Aplicando dito raciocínio à problemática do culto em rede, deve-se ressaltar que, no período pré-pandemia, também a eficácia do culto em rede era rejeitada ou, no mínimo, menosprezada. Mas, a imposição do distanciamento social assegurou seu uso, ainda que, preferencialmente, de modo remoto. Agora, percebe-se que o uso da rede revela experiências comunitárias mais complexas, até porque o fenômeno envolve

11 ADAM, J. C.; REBLIN, I. A.; SALDANHA, M. R., Igreja em rede e liturgia on-line, é possível?, p. 604.

12 ADAM, J. C.; REBLIN, I. A.; SALDANHA, M. R., Igreja em rede e liturgia on-line, é possível?, p. 604.

13 “Georg Wilhelm Friedrich Hegel (1770-1830) foi um filósofo alemão idealista que abriu novos campos de estudo na História, Direito, Arte, entre outros, através dos seus postulamentos e da lógica dialética. O pensamento de Hegel influenciou pensadores como Ludwig Feuerbach, Bruno Bauer, Friedrich Engels e Karl Marx”. BEZERRA, J., Hegel. 
interação digital. Como escreveu o psicanalista, escritor, teólogo e ex-pastor presbiteriano Rubem Alves, "quaisquer que sejam as realidades que me atingem, nada sei sobre elas, em si mesmas. Só as conheço como reverberações do meu corpo". ${ }^{14}$ Pois bem, o supracitado isolamento social trouxe igualmente como consequência a necessidade de se ponderar acuradamente sobre o corpo, em seus vários aspectos. Por isso, ao refletir sobre o interatuar dos meios midiáticos a partir do conhecimento on-life, torna-se óbvio que, nessa relação, a pessoa envolvida se deixa tocar também na sua realidade física, pois a sensibilidade que lhe é própria ali se manifesta (ou não) em sentimentos de empatia. Assim, malgrado seja mediada pela rede, trata-se sempre de comunidade de pessoas, motivo pelo qual dita relação virtual não conduz a uma liturgia sem vida ou sem corpo. É na existência de pessoas concretas, portanto, ainda que por meio da rede, é que se vivencia cada uma dessas experiências e, é pensando justamente nesta nova forma de comunidade, que as novas liturgias devem ser concebidas. ${ }^{15}$

Ao se "empoderar" desses recursos midiáticos, a Teologia encontrou respostas para dois questionamentos apresentados no início da pandemia da Covid-19. O primeiro deles indagava se era admissível celebrar uma cerimônia religiosa de modo online. A resposta é conhecida, pois as celebrações estão acontecendo também ao vivo pelas redes sociais. O segundo questionamento inquiria sobre e em que medida seria aceitável conduzir uma celebração verdadeiramente comunitária através da internet. A experiência por si só demonstrou essa viabilidade, sobretudo à medida que a igreja se familiarizou com os referidos recursos e concebeu o meio digital não como uma projeção de sua existência física, mas antes como um recurso tecnológico que não tem como preocupação primeira tais dicotomias, mas busca harmonizar pessoas e informática, ensejando uma espécie de "tridimensionalização da própria realidade". 16

A realidade mesma que se nos apresenta não pode, aliás, ser dividida em real e virtual, como se se compusesse de duas forças opostas, ou possuísse duas facetas paralelas que apenas se conectam estratégica e pontualmente na mídia. Ela se tornou concomitantemente real e virtual. Assim, a vida não se reduze a uma presença física restrita, mas se abre a outros espaços e tempos, tanto que

\footnotetext{
${ }^{14}$ ALVES, R., Variações sobre a vida e a morte, p. 31.

15 ADAM, J. C.; REBLIN, I. A.; SALDANHA, M. R., Igreja em rede e liturgia on-line, é possível?, p. 607.

16 ADAM, J. C.; REBLIN, I. A.; SALDANHA, M. R., Igreja em rede e liturgia on-line, é possível?, p. 607.
} 
imagens e gravações se perpetuam no tempo, mesmo que os protagonistas tenham expirado. Ademais, a civilização enquanto tal, fruto da evolução histórica coletiva, tem em cada indivíduo ou em cada corporeidade humana individual, um agente histórico transformador ou mesmo, produtor de realidades virtuais. ${ }^{17}$

Nesse panorama atual, uma igreja que insistir em modalidades anacrônicas, se condena à ruina e ao abstraimento esquecimento. A Teologia, da parte sua, mesmo sendo "a fé em forma de ciência", por estar igualmente ligada à vida humana que confessa a mesma fé, tampouco transcura a mencionada realidade real-virtual. Afinal, Cristo mesmo esclarece que "Deus se faz presente onde duas ou três pessoas invocam seu nome (Mt 18,20)", e isso vai além de distintos modelos. ${ }^{18}$

Partindo desses pressupostos, quando nos nossos dias se utiliza de forma adequada a linguagem digital, constata-se que ela de fato favorece celebrações comunitárias através da internet. Não se trata de transcrever preceitos, teorias e práticas várias, mas sim de traduzi-los para o hodierno contexto na forma digital e expressões afins. Tampouco se pretende extinguir ou abrir mão de elementos celebrativos consolidados, mas sim de aggiornare o mandamento de Cristo: "Ide, fazei discípulos de todas as nações, batizando-os em nome do Pai, e do Filho, e do Espírito Santo" (Mt 28,19-20). ${ }^{19}$

Insista-se, pois, que presidir cerimônias religiosas em rede não só supera a desnecessária divisão existente entre aquele que está conectado e entre o não conectado, como propicia a interatividade remota. Esta opção é producente, dado que os participantes têm ali a oportunidade de ouvir e opinar sobre questões provenientes da rede, as quais tantas vezes abreviam pretensões vividas na solidão dos espaços de isolamento. Ademais, passada a urgência de auxílio às comunidades em tempo de afastamento social, será necessário elaborar a síntese, dentro de um conhecimento mais extenso da comunidade, para daí planejar os ritos numa realidade de crise e de fé que aprendeu a dissolver as barreiras entre o presencial e o remoto, acreditando nas várias (e renovadas) maneiras de se viver a Encarnação. ${ }^{20}$

17 ADAM, J. C.; REBLIN, I. A.; SALDANHA, M. R., Igreja em rede e liturgia on-line, é possível?, p. 607-608.

18 ADAM, J. C.; REBLIN, I. A.; SALDANHA, M. R., Igreja em rede e liturgia on-line, é possível?, p. 608.

19 ADAM, J. C.; REBLIN, I. A.; SALDANHA, M. R., Igreja em rede e liturgia on-line, é possível?, p. 608.

${ }^{20}$ ADAM, J. C.; REBLIN, I. A.; SALDANHA, M. R., Igreja em rede e liturgia on-line, é possível?, p. 608 . 


\section{A ciberteologia}

A ciberteologia, neologismo popularizado graças ao padre jesuíta italiano Antônio Spadaro, busca qualificar a vivência e transmissão da fé nos tempos da triunfante internet. Como toda inovação, ela traz consigo propostas inéditas, mas abrindo também grandes discussões.

Inserem-se, nesta perspectiva, as rigorosas alterações sociais que em tempos recentes o novo coronavírus impôs a nível planetário, dado que a prática religiosa não se furtou de se adaptar às circunstâncias. Trata-se de uma reorientação relevante, considerando que numerosas instituições religiosas tiveram suas funções cultuais suspensas, para precaver os fiéis de um mal ameaçador, que continua a se alastrar sem que ainda se veja uma solução a curto prazo. ${ }^{21}$ A mesma situação coletiva, pelo viés da Teologia Prática, fez com que surgissem reflexões acerca da busca do divino na modalidade remota, uma vez que, não é secundário, o fato de os templos religiosos serem loci sociais. ${ }^{22}$

Como se viu, estamos na "era da comunicação midiática", em que realidades de pessoas conectadas e pessoas não conectadas se unem, influenciando todos os âmbitos da sociedade. Portanto, há uma propagação cultural jamais vista e nela, diferentes povos, antes separados ou confinados em seus próprios contextos, assistem a um inusual alargamento de horizontes. Surge daí um novo homem, designado digitalis. Deste modo, a famosa expressão cartesiana se reapresenta em roupagem nova, tipo "estou on-line, logo existo". 23

Para a Igreja, os desafios não terminam quando ela se "empodera" dessa novidade, realizando eficiente manejo dela. Permanece a necessidade de se fazer "bom uso" do digital para melhor apresentar o conteúdo evangélico. Ou seja, dominar a técnica do uso é indispensável, mas preparar para transmitir o conteúdo religioso no ciberespaço igualmente o é. Sabe-se, porém, que dito instrumento tecnológico tem possibilitado a afirmação de um ambiente cibernético que deveras está permitindo o encontro entre o fiel e o transcendente. Forma-se assim, pela internet, um novo espaço real, que não se reduz a um lugar particular no qual alguém adentra nalgum momento para depois dele sair e outra vez se integrar na vida off-line, uma vez que agora o que se tem é um novo jeito de se estar no planeta terra. ${ }^{24}$

${ }^{21}$ RIO, M. M. O., "Nos vemos on-line", p. 612.

${ }^{22}$ RIO, M. M. O., "Nos vemos on-line", p. 612.

${ }^{23}$ RIO, M. M. O., "Nos vemos on-line", p. 613.

${ }^{24}$ RIO, M. M. O., "Nos vemos on-line", p. 615. 
Lamentavelmente, sabe-se, contudo, que os recursos visuais disponíveis, quando usados com intenso apelo emocional podem estar mais localizados no coração do que na razão, ou seja, não colaboram com a racionabilidade e estruturação essencial da fé cristã. É o que sucede nos casos em que o enfoque se dá apenas no que festeja, impacta ou provoca forte impressão, ao invés de orientar para o que pode ser racionalmente envolvido e partilhado por diferentes indivíduos e ocasionar uma transformação factual de vida. Como alternativa para isso, o cristão da era digital, procura priorizar o apostolado, a cautela e o compartilhamento da fé ao transmitir seus conteúdos. Outra provocação atual que está exigindo respostas cristãs tem a ver com a banalização temática. ${ }^{25} \mathrm{Ou}$ seja, na tentação do "largo alcance", o conjunto dos costumes e hábitos fundamentais decai de nível, comprometendo a essência da mensagem por meio da frenética tentativa de se englobar tanto quanto possível a todos. ${ }^{26}$

Nesta mesma "cultura cibernética" ocorre, porém, uma abertura inédita e quase ilimitada para o anúncio da fé cristã. Isso torna possível a criação de uma área de influência que ultrapassa até mesmo as enormes igrejas como as de Lakewood, localizada na cidade texana de Houston, Estados Unidos, na qual seus mais de 52 mil fiéis, antes da Covid-19, se reuniam toda semana, ${ }^{27}$ mas, não há como impedir que esta nova forma de anúncio não tenha modificações e distorções da mensagem original. Por isso, é fundamental que o kérigma ${ }^{28}$ seja proclamado não somente como notícia e nem fique relegado apenas a uma informação, mas se torne um apelo à liberdade da pessoa humana que se reconhece em Cristo. ${ }^{29}$

No novo panorama que se impôs, destaca-se a anteriormente mencionada Teologia Prática, que, além de refletir uma sensibilidade eclesial, também aborda problemáticas outras, que superam os limites institucionais. Isso acontece na medida em que ela adentra na cultura social e pessoal hodierna. Esteja claro que atualmente há significados diversos para o conceito Teologia Prática, que não se confunde com a prática da teologia. ${ }^{30}$

O empoderamento da Teologia aconteceu em tal cenário de igreja, mídia e temporalidade, motivando atitudes de readaptação e inovação, como o fora

\footnotetext{
${ }^{25}$ RIO, M. M. O., "Nos vemos on-line”, p. 615.

${ }^{26}$ ANDREOLLA, J., A fé cristã na era digital, p. 80.

${ }^{27}$ CIO INSIGHT, Megachurch-megatech, the voice of the CIO Community.

28 "O termo querigma refere-se, de maneira panorâmica e sucinta, ao primeiro anúncio às pessoas que nunca ouviram o Evangelho e àqueles cristãos que carecem de uma formação cristã essencial que lhes permita viver conforme a fé". PUNTEL, J. T., Comunicação, p. 36.

${ }^{29}$ RIO, M. M. O., "Nos vemos on-line", p. 616.

${ }^{30}$ RIO, M. M. O., "Nos vemos on-line", p. 616.
} 
em díspares momentos na história da igreja. No caso, as distintas confissões, imersas num contexto pandêmico, tiveram que repensar seus modus vivendi a fim de assegurar a continuidade das atividades pastorais e a ação evangelizadora. Em se tratando especificamente da Igreja Católica, autoconcebendo-se como instituição viva e transmissora de uma verdade divinamente revelada, ela adequou-se às novas formas, sem abrir mão de seus princípios, malgrado vez por outra se manifeste o supracitado risco de se salientar demasiado o lado emotivo. Permaneceu, contudo, a prioridade de manutenção de dados fundamentais para o desenvolvimento da fé cristã, como a oração, a catequese e a assiduidade da comunidade, celebrados numa liturgia que abrange o culto racional referido pelo missionário Paulo ( $\mathrm{Rm} 12,1-2) .^{31}$

Nota-se igualmente que o uso "digital" da Teologia ensejou conveniências outras, ao alinhar o pensamento eclesial com a mentalidade corrente, coisa que se deu até mesmo em âmbito espiritual. Foi, aliás, em meio a esse conjunto de transformações ocorridas nas relações sociais que despontou a anteriormente citada ciberteologia, e esta, em conjunto com o ciberespaço, estimula um novo modo de se evangelizar, de se manter e "de se viver tanto no mundo off-line quanto no on-line". ${ }^{32}$ Insista-se, nesse sentido, que para isso o mesmo contexto pandêmico contemporâneo teve um peso relevante, uma vez que os chefes religiosos não o puderam ignorar. Adaptaram-se então às tecnologias digitais citadas em precedência, fato que favoreceu não somente novos modos de interpretar os signos, significados e semioses para se objetivar sentido, como também abriu caminhos novos para a propagação da mensagem do Evangelho. Daí, consolidaram-se, afinal, renovadas maneiras de se transmitir a Boa Nova, tal como nunca antes se vira, o que ultrapassou limites físicos e geográficos. Deste modo, torna-se lícito afirmar que o ciberespaço ora se apresenta não mais como simples instrumento suplementar, mas sim como um novo ambiente no qual os seguidores de distintos credos se congregam e compartilham experiências. Dentro da ciberteologia, entendida como teologia conectada ao ambiente digitalmente edificado, Jesus, se faz presente não somente de maneira espiritual, pois se tornou midiático. ${ }^{33}$

Como perspectiva futura, ao invés de se propor um retorno à normalidade anterior à pandemia, convém aderir à transformação verificada, o que implica inserção no processo histórico posto em marcha, o qual, em que pese suas dificuldades, também pode propiciar promissora autorreinvenção. Considere-

\footnotetext{
${ }^{31}$ RIO, M. M. O., "Nos vemos on-line", p. 622.

32 SBARDELOTTO, M., Deus digital, religiosidade online, fiel conectado, p. 34.

${ }^{33}$ RIO, M. M. O., "Nos vemos on-line”, p. 623-624.
} 
se que a nova normalidade impôs padrões inesperados, mas interessantes, e eles podem se constituir numa oportunidade para os seguidores de Cristo evangelizar nesses novos areópagos digitais que são as novas comunidades remotas na vida da igreja. Ou seja, ao invés de tentar suprimir a abrangência do fenômeno, os cristãos poderão dele se servir para portar a fé aonde ela antes não chegava. Assim, a luz do Evangelho será capaz de clarear os corações daqueles que ainda procuram em Cristo a via para bem conduzirem suas vidas. Um ângulo novo da visão da fé, também uma esperança a mais. ${ }^{34}$

\section{Do outro lado da "tela": a Igreja doméstica}

Graças aos recursos on-line, a igreja pode assistir espiritualmente e interagir com seus fiéis desde o início da pandemia. Isso aconteceu principalmente por meio da oração, da reflexão sobre a Palavra de Deus e dos cultos televisivos, radiofônicos e nos meios midiáticos. Tal procedimento contribuiu também para agilizar as reuniões dos chefes religiosos e estimulou iniciativas pastorais, instruções formativas para as diversas áreas da evangelização, e medidas mais. Enquanto instituição, a Igreja desenvolveu assim formas novas de atuação, o que lhe consentiu de estar eficazmente presente nos lares e na vida dos crentes, que igualmente retribuíram ao reclamo feito. ${ }^{35}$

A Pastoral da Comunicação, nesse ínterim, atuou igualmente como "alavanca de empoderamento" não só como instrumento de apoio para a fixação do uso dos referidos meios, mas também por incentivar a adesão das famílias. Tudo ajudou a reforçar a Igreja doméstica, pois os membros das famílias reacostumaram a permanecer juntos e juntos rezarem, dividindo outrossim outros aspectos de interesse comum. Ainda que não se dessem a elaborações conceituais, na prática o sacerdócio comum dos lares foi reavivado, pois pais e filhos, diante de uma simples "tela tecnológica" resgataram valores como a partilha da fé entre batizados do mesmo núcleo. Além do mais, reforçou salutares afetos, indispensáveis ante a onipresente ameaça da covid-19, e de todo o clima de ansiedade que tal situação suscita. ${ }^{36}$

Nestas circunstâncias, a Igreja exercitou deveras um papel relevante, não só por oferecer conforto espiritual, mas principalmente por se tornar instrumento de esperança para quantos a seguem. Conjuntamente, a teologia se

\footnotetext{
${ }^{34}$ RIO, M. M. O., "Nos vemos on-line", p. 624.

${ }^{35}$ COSTA, P. C., Pandemia e pós-pandemia.

${ }^{36}$ COSTA, P. C., Pandemia e pós-pandemia; OLIVEIRA, M. D., Cuidado pastoral da Igreja em tempos de pandemia, p. 267.
} 
fez oferta, proposta, luz e vida, e assim, também ela, utilizando-se dos meios online, não titubeou em colocar à disposição o grande patrimônio intelectual e espiritual de que dispõe, coisa que serviria de base inclusive para o desenvolvimento de várias formas de assistência em âmbito social. Não foi uma iniciativa menor, se se considera os traumas das pessoas que emergiram em decorrência do isolamento social. Isto porque este novo estado de coisas, infelizmente colaborou para o aumento das dissoluções matrimonias e até da violência familiar que, não raro, teve nas mulheres, nas crianças e nos idosos suas principais vítimas. Indubitavelmente, o aconselhamento pastoral influiu também aí, ajudando a minorar o drama da Igreja doméstica. ${ }^{37}$

De outra feita, os novos tempos paralelamente propiciaram a firme atuação de muitos católicos, "engajados" nas ruas e também em condomínios, conjuntos habitacionais, vilarejos e até em algumas aldeias, o que consentiu na formação de autênticas igrejas virtuais. Além disso, a ação deles fez multiplicar os pequenos grupos atuantes e células de fé. Em vários casos, as próprias famílias nucleares assumiram este perfil, pois, como se viu, a igreja doméstica também saiu reforçada, recordando as primeiras comunidades relatadas em Atos dos Apóstolos. ${ }^{38}$ Destaque-se aqui o potencial das mulheres, protagonistas na iniciativa de se reunir a família para buscar o sagrado no cotidiano de suas casas. $\mathrm{Na}$ visão feminista da teóloga britânica Tina Beattie, apareceu uma Igreja doméstica que desfez fronteiras entre a liturgia formal, mediada por um sacerdote exclusivamente masculino, ${ }^{39}$ e um mundo doméstico mais informal, de celebrações caseiras e cultos repentinos, várias vezes orientados por mulheres.

Certo é que a Igreja doméstica fez com que os pais habituados a um limitado convívio com os filhos, agora se encontrassem juntos praticamente vinte e quatro horas por dia de convivência com eles e vice-versa, devendo repartir suas atividades profissionais com a educação e brincadeiras deles, numa atenção inusual à prole e à vida cristã. Vale dizer: os pais tiveram de se "reinventar" para levar a cabo as funções domésticas e cuidado dos filhos, estabelecendo novos critérios vivenciais do quotidiano. Dito período, portanto, não obstante o contesto externo adverso, se tornou rico de oportunidades para que as famílias reavivassem a convivência interna. Em boa parte das vezes, portanto, houve um amadurecimento das próprias interrelações para o que também a Igreja deu seu contributo, dado que, a rica tradição que esta possui,

${ }^{37}$ COSTA, P. C., Pandemia e pós-pandemia.

${ }^{38}$ COSTA, P. C., Pandemia e pós-pandemia.

${ }^{39}$ BEATTIE, T., As mulheres e a Igreja pós-pandemia. 
no tocante a orientação e enriquecimento poimênico, ${ }^{40}$ foi colocada à disposição. ${ }^{41}$

Neste sentido, a pastoral da comunicação para a vida eclesial exerceu notável papel orientativo em âmbito midiático. A isso deve ser acrescentada a ação da pastoral da família que, nos dias atuais, tem assumido relevante papel na formação das consciências. Seu trabalho, no caso, é realmente delicado, dada a complexidade da realidade brasileira e a variedade das condições sociais de cada um dos núcleos familiares que compõem. Outro elemento complicador decorre do conhecido fato que períodos de isolamento social são propícios para a elevação ou aparecimento de distúrbios psíquicos, o que supõe quadros depressivos, ansiosos e compulsivos, estresses, etc. ${ }^{42}$ Situações do gênero não são raras e quando elas se manifestam, criam tensões nos lares, provocando variações de humor individuais ou mesmo conflitos mais abrangentes. Nesse sentido, o mesmo período de confinamento, ainda em curso, pode estimular ou reforçar anomalias comportamentais tipo ingestão exagerada de bebidas alcoólicas, hipocondria e estados de ânsia. ${ }^{43}$

Tal conjuntura de modo algum justifica, mas até certo ponto explica, certas manifestações de violência doméstica, que tantas vezes vitimiza mulheres e crianças, além de provocar sequelas graves naqueles que se encontram submetido a ela. A ONU mesma, aliás, adverte sobre o crescimento dos atritos de gênero verificados em determinados países feridos pela Covid19, sem excluir o Brasil. O alerta se torna ainda mais grave também porque, em paralelo, tem aumentado os casos de feminicídio. ${ }^{44}$

Não indiferente a quanto ocorre, a Igreja, enquanto "mãe e mestra", como acima se viu, tem se empenhado em organizar uma pastoral bem direcionada para tanto. A tarefa não é simples, pois, de um lado é imperioso não "cair na tentação" de tentar reproduzir modelos anacrônicos e puritanos, mas doutro, não se pode pura e simplesmente legitimar quanto se apresenta. Assim, para ser fiel a si mesma e responder aos novos tempos, a pastoral da família se tornou outra organização eclesial que não titubeia em se "empoderar" dos canais online para melhor levar adiante sua ação junto às famílias. Isso tem acontecido por meio da formação virtual para as famílias em isolamento, na orientação remota, e em catequeses e formações bíblicas virtuais também voltadas para

${ }^{40}$ CLINEBELL, H. J., Aconselhamento pastoral, p. 251-252.

${ }^{41}$ OLIVEIRA, M. D., Cuidado pastoral da Igreja em tempos de pandemia, p. 267.

${ }^{42}$ SCHMIDT, B. et al., Impactos na saúde mental e intervenções psicológicas diante da pandemia do novo coronavírus (COVID-19), p. 1-26.

${ }^{43}$ OLIVEIRA, M. D., Cuidado pastoral da Igreja em tempos de pandemia, p. 267.

${ }^{44}$ OLIVEIRA, M. D., Cuidado pastoral da Igreja em tempos de pandemia, p. 268. 
núcleos familiares. É dada ainda a atenção possível à saúde psíquica dos orientados, em certos casos, ligados à dependência química e alcoolismo, e se busca ensejar domicílios sem violência, num clima de espiritualidade condizente para cada situação. ${ }^{45}$

Portanto, observa-se que, mesmo do outro lado da tela dos meios midiáticos, a igreja doméstica acolheu e recebeu um suporte importante da ação pastoral familiar para ressignificar o modo de viver nestes tempos de desafios diante da crise sanitária e econômica do país, momento em que muitos lares sentiram ou ainda sentem temores, tensões e insegurança. Por conseguinte, sem descuidar dos valores de sua tradição, pelas razões indicadas, a Igreja se lançou nesta nova perspectiva pró-família, visando responder aos desafios apresentados pelo tempo em que vive. ${ }^{46}$

\section{A teologia urge em ser profética}

As situações de crise, como a atual pandemia, geram dúvidas, anomalias interpretativas e vozes dissonantes não raro eivadas de discursos inconciliáveis com a proposta cristã de vida. Isso impõe a necessidade de maior discernimento religioso não só para coibir excessos, mas principalmente para oferecer alternativas válidas a esta e outras situações análogas. Afinal, orientada pelo evangelho, a Igreja em missão tampouco se esquece de sua tarefa profética no exercício da pastoral. ${ }^{47}$

Em conjunturas como a que hoje se vive, a reflexão teológica se torna um verdadeiro manancial, por oferecer elementos de reflexão, essenciais para o amadurecimento de alternativas. Isso evita, por exemplo, que nas citadas circunstâncias adversas, predomine o pessimismo ou posturas individualistas e se busque, ao contrário, o bem coletivo, inclusive por meio do incentivo às já articuladas medidas de prevenção postas em ato. Nesse particular, como foi visto em precedência, os meios de comunicação midiáticos eclesiais dão inestimável contributo para a conscientização da necessidade do isolamento social, que é sabidamente um eficaz instrumento para a contenção de um mal pandêmico que persiste. ${ }^{48}$

Ainda sobre a teologia, por propiciar ela a harmonia entre fé e razão, contribui igualmente para o esclarecimento de muitos. Isso se dá sobretudo

\footnotetext{
${ }^{45}$ OLIVEIRA, M. D., Cuidado pastoral da Igreja em tempos de pandemia, p. 268.

${ }^{46}$ OLIVEIRA, M. D., Cuidado pastoral da Igreja em tempos de pandemia, p. 268.

${ }^{47}$ OLIVEIRA, M. D., Cuidado pastoral da Igreja em tempos de pandemia, p. 270

${ }^{48}$ OLIVEIRA, M. D., Cuidado pastoral da Igreja em tempos de pandemia, p. 270-271.
} 
entre as pessoas de melhor condição econômica e intelectual, instadas como são para que, dentre outras coisas, evitem excessos nas aquisições, para não provocarem desabastecimentos de produtos nos comércios, afetando a vida de outros tantos, de modo especial dos menos favorecidos. Nesse sentido, o apelo a um acordo solidário tem se transformado num verdadeiro imperativo categórico, num momento em que a Igreja, assim como a inteira sociedade, tem sido interpelada para que incentive ou colabore com as associações que estimulam indivíduos e empresas ligadas à assistência ou promoção dos extratos sociais frágeis. ${ }^{49}$

Podem também as entidades religiosas, através de seus membros e associações afins, organizar nos locais de que dispõem, conferências virtuais sobre os projetos em andamento e assim arquitetar no hoje e no pós-Covid-19, ações conjuntas com quantos compartilhem dos mesmos ideais que professam. A ação social encontra, aliás, base de apoio também na Teologia, pois o apelo ao transcendente se coaduna com os mecanismos de ação pastoral, tidos como expressão da fé cristã, se bem vivenciada como vocação ativa da religiosidade pública e cidadã. ${ }^{50}$ Afinal, aos batizados Cristo confiou a responsabilidade de anunciar concretamente a todos as boas novas do Reino vindouro. ${ }^{51}$

Sempre em relação à estatura profética da Teologia, que tantos "frutos de graça" enseja, ela tem de modo profícuo encorajado as igrejas a promoverem reuniões, simpósios e congressos virtuais diversos, mirando ao aperfeiçoamento das ciências e reflexões sobre o desempenho das pastorais mesmo quando o contexto, a exemplo do atual, não se apresenta favorável. Ou seja, não descuida do papel público que tem e se serve do próprio arcabouço reflexivo para orientar pessoas e entidades. Isso se estende às administrações públicas, empresas, organismos sociais e à própria ciência, haja visto que a pesquisa empírica e a reflexão sobre Deus e credos atingiram bom nível de respeito recíproco. Daí, está em andamento uma série de diligências em que a Teologia oferece contributos, tais como nas áreas da economia, saúde, bioética e outras mais. ${ }^{52}$

Ao mesmo tempo, como sendo manifestação e enriquecimento da "instituição igreja", a Teologia volta igualmente sua atenção para a seara política, exortando a atenção de governos para que adotem o necessário cuidado em relação à vida. Daí seu apelo aos dirigentes da "ordem estabelecida" a fim de que auxiliem de forma concreta aos cidadãos vulneráveis e criem para eles

\footnotetext{
${ }^{49}$ OLIVEIRA, M. D., Cuidado pastoral da Igreja em tempos de pandemia, p. 271.

${ }^{50}$ CASTRO, C. P., Por uma fé cidadã, p. 107.

${ }^{51}$ OLIVEIRA, M. D., Cuidado pastoral da Igreja em tempos de pandemia, p. 271.

52 OLIVEIRA, M. D., Cuidado pastoral da Igreja em tempos de pandemia, p. 271.
} 
justas condições de vida e trabalho. ${ }^{53}$ Procedendo assim, reforça a teologia as ricas experiências históricas de superação, que tanto estimularam povos para o recomeço. ${ }^{54}$

Vale ressaltar, por fim, que o anúncio que faz a Teologia ressoa para ela própria, mesmo quando tal sucede em formas novas, como no caso da internet. A razão é que uma iniciativa abre caminho para continuidades outras e convidam igualmente a refletir sobre atitudes pouco condizentes com a retidão evangélica. Trata-se, por exemplo, daqueles setores denominacionais cristãos e de certas lideranças religiosas que, minimizando a gravidade do presente drama pandêmico, priorizam o corporativismo, comprimindo alguns políticos para abertura de templos. ${ }^{55}$ A coerência para com o chamado divino recebido, certamente inspiram valores de matriz diversa. ${ }^{56}$

\section{Conclusão}

A acometida pandêmica iniciada a partir de 2019 impôs novas normas de conduta a nível global, fato este que afetou profundamente as próprias relações humanas, agora condicionadas pelo isolamento social. O exercício mesmo da fé teve que ser reconsiderado, tendo este encontrado alternativas para se expressar nas redes tecnológicas. Diga-se ainda, que, na busca pela adequação ao presente contexto, as instituições obtiveram notável êxito no tocante à aproximação com os fiéis. ${ }^{57}$ Descobriu-se assim, neste contexto da pandemia, uma nova configuração eclesial, que "transferiu" a experiência da fé dos templos para as casas. É preciso enxergar este fato como uma ocasião para refletir formas de pleno funcionamento da vida da Igreja, o que remonta às próprias fontes e origens do cristianismo. Nos lares, agora, os fiéis se agregam por meio da internet e recompõem o espaço familiar, enriquecendo-o com a celebração da fé.

É necessário, portanto, confirmar que a família, como igreja doméstica, necessita ser analisada e é fundamental que diante do impedimento de frequentar os templos, principalmente para pessoas idosas ou com comorbidades, tais famílias afirmem sua identidade de igrejas domésticas. O afastamento social faz lembrar, de maneira especial, os familiares que estão

\footnotetext{
${ }^{53}$ FERRARI, A.; CUNHA A. M., A pandemia de Covid-19 e o isolamento social.

${ }^{54}$ OLIVEIRA, M. D., Cuidado pastoral da Igreja em tempos de pandemia, p. 272.

${ }^{55}$ CUNHA, M., Diante da crise do coronavírus, o que as igrejas podem fazer.

${ }^{56}$ OLIVEIRA, M. D., Cuidado pastoral da Igreja em tempos de pandemia, p. 272.

${ }^{57}$ PINTO, F. L. S., A Igreja Católica Apostólica Romana e os veículos de comunicação.
} 
praticamente há um ano sem se relacionar com os seus parentes e amigos. Deste modo, os templos religiosos não podem se resumir exclusivamente aos templos físicos, restritos a uma edificação, mas deve estar dentro dos lares.

No evangelho de Mateus, Jesus proclama: "onde dois ou três estiverem reunidos em meu nome, aí estou eu, no meio deles" (Mt 18,20). Ainda neste evangelho, Jesus consola os seus: "eis que ficarei convosco todos os dias até o fim do mundo" (Mt 28,20). Assim, desde a encarnação até a Ascenção do Senhor, a mesma insistência: Deus está com seu povo, mesmo quando este é pouco numeroso, e não o abandonará.

Quando a vivência do ser Igreja se dá no ambiente doméstico, ressaltase a importância dos cristãos leigos e leigas, batizados que se colocam como os grandes intérpretes da mensagem cristã. De início, isso teria um grande valor para quebrar o clericalismo, tão criticado pelo atual pontífice. A espiritualidade dos leigos traz uma particularidade muito bela que é a de não prescindir da vida vivida. Na Teologia Prática dos leigos, estão o emprego, a educação, a saúde, o alimento, a lembrança dos falecidos, e tantas outras motivações. As pessoas são lembradas pelo nome. O oposto disso é um rigor excessivo pela firmeza dogmática, uma teologia perfeita, mas abstrata, que não toca a existência e não convida a viver. A Igreja doméstica é efetiva, fala da vida como ela é, ainda que tenha falhas na interpretação bíblica, práticas inerentes ao culto e teológicas, ali está Deus, como "alguém lá de casa". Por isso, seja de modo presencial ou virtual a Teologia estará presente na casa e na vida das pessoas, aliás, sempre esteve presente de modo presencial, agora ganhou força, empoderou-se, isto é, tem sua investidura celestial não apenas na vida dos cristãos, mas também nos recursos midiáticos.

Se as novas mídias já eram importantes, agora, a igreja doméstica está diretamente relacionada a elas. Ao refletir sobre a Ciberteologia, refulge a finitude, ao manifestar o desejo de infinito, de divino, num campo em que espiritualidade e a tecnologia se cruzam. No fundo, as redes sociais trouxeram muitos componentes da área religiosa, como pode-se notar nas palavras salvar, converter e justificar. $\mathrm{Ou}$ seja, unir religião e internet pode não ser tão forçado assim.

\section{Referências Bibliográficas}

ADAM, J. C.; REBLIN, I. A.; SALDANHA, M. R. Igreja em rede e liturgia on-line, é possível? Estudos Teológicos, v. 60, n. 2, p. 598-609, mai./ago. 2020 .

Disponível

em: 
$<$ file://C:/Users/User/Downloads/IGREJA_EM_REDE_E_LITURGIA_ONL INE_E_POSSIVEL.pdf $>$. Acesso em: 04 jan. 2021.

ALVES, R. Variações sobre a vida e a morte: a teologia e a sua fala. São Paulo: Loyola, 2005.

ANDREOLLA, J. A fé cristã na era digital: Diálogo entre a revelação na tecnologia de Bruno Forte e a experiência religiosa na Internet. Porto Alegre, 2012. 80p. Dissertação. Faculdade de Teologia, Pontifícia Universidade Católica do Rio Grande do Sul.

BÍBLIA de Jerusalém. Nova ed. rev. e ampl. 2. impr. São Paulo: Paulus, 2003.

BEATTIE, T. As mulheres e a Igreja pós-pandemia. Revista IHU On-Line, São Leopoldo, 5 jun. 2020. Disponível em: <http://www.ihu.unisinos.br/78noticias/599690-as-mulheres-e-a-igreja-pos-pandemia-artigo-de-tina-beattie $>$. Acesso em: 04 jan. 2021.

BEZERRA, J. Hegel. Disponível em: $<$ https://www.todamateria.com.br/george-wilhelm-friedrich-hegel/>. Acesso em: 03 jan. 2021.

CAMPOS, L. S. Igrejas cristãs brasileiras e cultura midiática: omissões, tensões e oportunidades. In: ADAM, J. C.; REBLIN, I. A. (Orgs.). Religião, mídia e cultura. São Leopoldo: Sinodal, 2015. p. 123-168. v. 1.

CASTRO, C. P. Por uma fé cidadã: a dimensão pública da Igreja fundamentos para uma Pastoral da Cidadania. São Bernardo do Campo: Editora da Umesp; São Paulo: Loyola, 2000.

CIO INSIGHT. Megachurch-megatech, the voice of the CIO Community. Disponível em: <https://www.cioinsight.com/c/ a/Trends/MegachurchMegatech>. Acesso em: 03 jan. 2021.

CLINEBELL, H. J. Aconselhamento pastoral: modelo centrado em libertação e crescimento. São Paulo: Paulus; São Leopoldo: Sinodal, 1998.

COSTA, P. C. Pandemia e pós-pandemia: dez pontos para reflexão. Disponível em: <https://franciscanos.org.br/vidacrista/pandemia-e-pospandemia-dez-pontos-para-reflexao/\#gsc.tab=0>. Acesso em: 05 jan. 2021.

CUNHA, M. Diante da crise do coronavírus, o que as igrejas podem fazer? Carta Capital, 24 mar. 2020. Disponível em: 
$<$ https://www.cartacapital.com.br/blogs/dialogos-da-fe/diante-da-crise-docoronavirus-o-que-as-igrejas-podem-fazer/> Acesso em: 05 jan. 2021.

FERRARI, A.; CUNHA A. M. A pandemia de Covid-19 e o isolamento social: saúde versus economia. UFRGS, Rio Grande do Sul, 28 mar. 2020. Disponível em: $<$ https://www.ufrgs.br/coronavirus/base/artigo-a-pandemia-de-covid-19-eo-isolamento-social-saude-versus-economia/ > Acesso em: 04 jan. 2021.

OLIVEIRA, M. D. Cuidado pastoral da Igreja em tempos de pandemia: Covid19. Revista Caminhando, v. 25, n. 1, p. 257-276, jan./abr. 2020. Disponível em: $<$ https://www.metodista.br/revistas/revistasims/index.php/Caminhando/article/viewFile/10336/7240>. Acesso em: 03 jan. 2021.

PINTO, F. L. S. A Igreja Católica Apostólica Romana e os veículos de comunicação. Disponível em: $<$ https://www.nucleodoconhecimento.com.br/ciencia-da-religiao/veiculos-decomunicacao>. Acesso em: 03 jan. 2021.

PUNTEL, J. T. Comunicação: diálogo dos saberes na cultura midiática. São Paulo: Paulinas, 2010.

SBARDELOTTO, M. Deus digital, religiosidade online, fiel conectado: Estudos sobre religião e internet. Cadernos Teologia Pública, v. 9, n. 70, p. 540, 2012. Disponível em: $<$ http://www.ihu.unisinos.br/images/stories/cadernos/teopublica/070cadernost eologiapublica.pdf $>$. Acesso em: 03 jan. 2021.

RIO, M. M. O. "Nos vemos on-line": diferentes vozes sobre a busca por Deus no cenário pandêmico brasileiro. Estudos Teológicos, v. 60, n. 2, p. 610-626, mai./ago. 2020. Disponível em: <file://C:/Users/User/Downloads/404815952-1-PB.pdf>. Acesso em: 04 jan. 2021.

SCHMIDT, B. et al. Impactos na saúde mental e intervenções psicológicas diante da pandemia do novo coronavírus (COVID - 19). Revista Estudos de Psicologia, v. 16, n. 4, p. 1-26, 2020.

SPADARO, A. Ciberteologia: pensar o cristianismo nos tempos da rede. São Paulo: Paulinas, 2012. 


\section{Fábio Luiz Ribeiro}

Doutorando em Teologia pela Pontifícia Universidade Católica de São Paulo São Paulo / SP - Brasil

E-mail: fabioosm@gmail.com

Recebido em: 22/02/201 Aprovado em: 09/08/2021 